\title{
The Raven's Advanced Progressive Matrices in Education Assessment with a Rasch Analysis
}

\author{
Nurhudaya, Agus Taufik, Eka Sakti Yudha*, Dodi Suryana
}

Department of Guidance and Counseling, Universitas Pendidikan Indonesia, Indonesia

Copyright $\bigcirc 2019$ by authors, all rights reserved. Authors agree that this article remains permanently open access under the terms of the Creative Commons Attribution License 4.0 International License

\begin{abstract}
The study aimed to evaluate the Advanced Progressive Matrices (APM) with a Rasch analysis to enhance the precision of the instrument. Accurate assessment of a student potential ability is essential for the timely provision of guidance and counseling support. The Advanced Progressive Matrices (APM) is an ordinal measure possessing acceptable psychometric properties, but its ability to discriminate precisely between individual potential levels has not been rigorously investigated. The quantitative approach involved respondent of 12,343 students in West Java, Indonesia. The data analysis used the partial credit Rasch model. This study uses Raven's Advanced Progressive Matrices instruments. The results of this study which are achieved through Initial analysis supported the use of the Rasch model and acceptable reliability (Alpha Cronbach $=0.85$ ) was observed. Person reliability is 0.86 , item reliability is 1.00 . Local dependency between items through the creation of super-items increased model fit, person separation index = 2.35, and unidimensional. In fit and outfit statistics, all items satisfied the criterion for construct validity. Almost all items except 17, 21, and 36 had suitable point-measurement correlation, reflecting content validity. Item characteristic curves indicated that roughly 36 items were evenly distributed along the person ability continuum. The modified APM showed excellent reliability for a measure in assessing the overall potential ability of the students. The item would be added related to the person ability estimates. And several items should be omitted to ensure construct validity. Practically, APM is still relevant to assess the potential ability.
\end{abstract}

Keywords The Raven's Advanced Progressive Matrices, Education, Assessment, Rasch Analysis

\section{Introduction}

The experts have provided an explanation of the nature and understanding of intelligence through various approaches. The approach in question is a philosophical, pragmatic, theoretical and operational approach $[1,2,3]$. In a philosophical approach, intelligence is explained through reflection, logical thinking, and intuitiveness. The pragmatic approach sees situational intelligence starting from its usefulness [1].Reference [4] states that "Intelligence is what is measured by intelligence tests". The theoretical approach explains intelligence theoretically to the factors implicit in intelligence. For example, Reference [5] divides the description of intelligence into explanations that emphasize (a) adaptability to the environment, (b) capacity to learn, and (c) skills for abstract thinking. In a relationship with the understanding of the intellect, Reference [6] defines general intelligence as general mental adaptability to problems of living conditions. Reference [7] provides a formula for understanding intelligence which is almost the same as 'individual skills to adapt themselves adequately to new situations in life.

In the explanation above, it seems that the urgency of intelligence for individual success, with these assumptions, the researchers began to develop various tests to uncover intelligence, one of which was John C. Raven (1963) [8] who tried to make a set of tests to reveal neutral intelligence from cultural influences, then selected a number of graphics arranged with varying degrees of difficulty. Advanced progressive matrix (APM) is a standardized cognitive ability test that was designed to measure general intelligence [4]. Non-verbal intelligence tests are used massively, especially in the world of education [6]. In Indonesia, APM has been used since the 1980s, especially for school admission and specialization services. In addition, APM is also used for networking academic gifted students [9].

The APM consists of 48 items (Set $\mathrm{I}=12$; Set $\mathrm{II}=36$ items) which are arranged progressively by presenting missing geometric images in one part $[10,11]$. APM has several advantages including being able to be used in group tests; requires a relatively short time; not biased towards culture; can describe abstract reasoning and general intelligence ("g" factor). APM has been used in education assessments 
in Indonesia for more than 39 years, but until now there has been no structured psychometric evaluation. In this study, Rasch models are used as tools for analyzing psychometric constructs from APM $[12,13,14]$. The Rasch models are used because this model can provide solutions to the limitations possessed by classical models. As for example in the classical model, reliability depends on the sample; as criticized by Reference [15], the classical reliability in the test does not always have to be expected because of the sample dependency, the non-linear raw score, the restriction in the range of scores, negative and positive inter-item correlation and rubric scoring [10].

Current research aims to provide up-to-date information on the reliability and validity of APM in the Indonesian context. This research can be used as a reference to determine whether APM has psychometric properties, in this case, reliability and validity, which is adequate. This is certainly in line with efforts to give consideration to the relevance of the use of APM in Indonesia today. To prove validity, this study uses a modern test with items response theory.

\section{Research Method}

\subsection{Participant}

The sample of this research was random where a selected of 36 senior high schools in West Java province-Indonesia. Schools 12.343 student (Male=5.230, Female $=7.113$ ) of various ability but of the same age group (Table 1).

Table 1. Person Groups for DIF Analysis

\begin{tabular}{|c|c|c|}
\hline Gender & Age Group & Category \\
\hline & & Genius $(n=741)=6 \%$ \\
Male $(n=5.230)$ & & Superior $(n=2098)=17 \%$ \\
Female & 16 to 19 years of & Above average \\
$(n=7.113)$ & age & $(n=3333)=27 \%$ \\
$\mathrm{~N}=12.343$ & & Average $(n=5554)=45 \%$ \\
& & Below average \\
& & $(n=617)=5 \%$ \\
\hline
\end{tabular}

\subsection{Procedure}

This study uses Raven's Advanced Progressive Matrices instruments set I and II, although for the purposes of this study, APM set II was studied further with 36 items. Administration of APM is relatively fast with detailed verbal instructions [10]. APM is included in the category of non-verbal tests consisting of two sets, and each has a different duration.

The raw APM data is collected from the database owned by the UPI Psychology Education and Guidance Laboratory. The data obtained amounts to 12,343 data, which is from 2017-2018. The raw data is then verified and processed into data ready for further processing using Winstep.

\section{Result and Discussion}

\subsection{Summary Statistics}

Overall, APM has reliable reliability (Cronbach Alpha $=0.85)$, with the average score obtained $(\mathrm{x}=-0.11)$ which means that student ability is generally below the standard difficulty level of the question. The consistency of the answers of the respondents was very good (Person reliability $=0.86$ ) with the quality of the items that were very good (reliability items $=1.00$ ).

If analyzed further, there are several things that will affect the quality of test scores, especially psychological test scores. In addition to the quality of the instrument test, these are (1) the test taker (who does it, the expert or who), (2) the person being tested (test conditions, etc.), (3) administration (corrector, answer key, the score taker, and the score recording process), (4) test time recording, and (5) the atmosphere of the test itself. With regard to the implementers of the test, the person carrying out the psychological examination is the key objectivity about the data obtained; therefore, in this study, a number of trained testers were involved who were equipped with a number of competencies to be able to administer the test appropriately so that the results obtained could be ensured from human error.

Table 2. Summary of All Rasch Model Person Statistics (Summary of 12.343 MEASURED Person)

\begin{tabular}{|c|c|c|c|c|c|c|c|c|}
\hline & \multirow{2}{*}{$\begin{array}{l}\text { Total } \\
\text { Score }\end{array}$} & \multirow{2}{*}{ Count } & \multirow{2}{*}{ Measure } & \multirow{2}{*}{$\begin{array}{c}\text { Model } \\
\text { Error }\end{array}$} & \multicolumn{2}{|c|}{ Infit } & \multicolumn{2}{|c|}{ Outfit } \\
\hline & & & & & MNSQ & ZSTD & MNSQ & ZSTD \\
\hline MEAN & 17.4 & 35.6 & -.11 & .43 & .99 & -.1 & 1.11 & .1 \\
\hline S.D. & 6.3 & 1.5 & 1.16 & .06 & .22 & 1.1 & .79 & 1.1 \\
\hline MAX. & 35.0 & 36.0 & 4.44 & 1.07 & 2.03 & 3.9 & 9.90 & 5.0 \\
\hline MIN. & 1.0 & 14.0 & -4.36 & .40 & .44 & -3.5 & .17 & -2.9 \\
\hline \multicolumn{2}{|c|}{ Real RMSE } & \multicolumn{2}{|c|}{.46 TRUE SD } & \multicolumn{3}{|c|}{ 1.07 Separation 2.35} & \multicolumn{2}{|c|}{ Person RELIABILITY .85} \\
\hline \multicolumn{2}{|c|}{ Model RMSE } & \multicolumn{2}{|c|}{.44 TRUE SD } & \multicolumn{3}{|c|}{ 1.08 Separation 2.46} & \multicolumn{2}{|c|}{ Person RELIABILITY .86} \\
\hline & \multicolumn{8}{|c|}{ S.E of Person MEAN $=.01$} \\
\hline
\end{tabular}


Table 3. Summary of All Rasch Model Item Statistics (SUMMARY OF 12.343 MEASURED Person)

\begin{tabular}{|c|c|c|c|c|c|c|c|c|}
\hline & \multirow{2}{*}{$\begin{array}{l}\text { Total } \\
\text { Score }\end{array}$} & \multirow{2}{*}{ Count } & \multirow{2}{*}{ Measure } & \multirow{2}{*}{$\begin{array}{c}\text { Model } \\
\text { Error }\end{array}$} & \multicolumn{2}{|c|}{ Infit } & \multicolumn{2}{|c|}{ Outfit } \\
\hline & & & & & MNSQ & ZSTD & MNSQ & ZSTD \\
\hline MEAN & 5959.3 & 12209.3 & .00 & .02 & .99 & -.6 & 1.12 & 1.5 \\
\hline S.D. & 3055.7 & 170.6 & 1.44 & .00 & .08 & 6.2 & .36 & 7.4 \\
\hline MAX. & 10390.0 & 12340.0 & 3.03 & .04 & 1.13 & 9.3 & 2.78 & 9.9 \\
\hline MIN. & 743.0 & 11624.0 & -2.19 & .02 & .84 & -9.9 & .71 & -9.9 \\
\hline \multicolumn{2}{|c|}{ Real RMSE } & \multicolumn{2}{|c|}{.02 TRUE SD } & \multicolumn{3}{|c|}{ 1.44 Separation 59.29} & \multicolumn{2}{|c|}{ Item RELIABILITY .1.00 } \\
\hline \multicolumn{2}{|c|}{ Model RMSE } & \multicolumn{2}{|c|}{.02 TRUE SD } & \multicolumn{3}{|c|}{ 1.44 Separation 60.28} & \multicolumn{2}{|c|}{ Item RELIABILITY .1 .00} \\
\hline \multicolumn{9}{|c|}{ S.E of Person MEAN $=.01$} \\
\hline
\end{tabular}

Table 4. Item Statistics: Misfit Order

\begin{tabular}{|c|c|c|c|c|c|c|c|c|c|c|c|c|c|}
\hline \multirow{2}{*}{$\begin{array}{l}\text { Entry } \\
\text { Number }\end{array}$} & \multirow{2}{*}{$\begin{array}{l}\text { Total } \\
\text { Score }\end{array}$} & \multirow{2}{*}{$\begin{array}{l}\text { Total } \\
\text { Count }\end{array}$} & \multirow{2}{*}{ Measure } & \multirow{2}{*}{$\begin{array}{l}\text { Model } \\
\text { S.E. }\end{array}$} & \multicolumn{2}{|c|}{ Infit } & \multicolumn{2}{|c|}{ Outfit } & \multicolumn{2}{|c|}{ PT-Measure } & \multicolumn{2}{|c|}{ Exact Match } & \multirow{2}{*}{ Item } \\
\hline & & & & & MNSQ & ZSTD & MNSQ & ZSTD & CORR. & EXP. & OBS $\%$ & EXP\% & \\
\hline 36 & 743 & 11624 & 3.03 & .04 & 1.13 & 4.0 & 2.78 & 9.9 & A .05 & .24 & 93.5 & 93.7 & I0036 \\
\hline 32 & 1873 & 11924 & 1.93 & .03 & 1.09 & 5.4 & 1.66 & 9.9 & B .22 & .34 & 84.5 & 85.0 & I0032 \\
\hline 29 & 1652 & 12118 & 2.13 & .03 & 1.07 & 3.7 & 1.64 & 9.9 & C. .23 & 32 & 86.6 & 86.8 & I0029 \\
\hline 28 & 1992 & 11883 & 1.83 & .03 & 1.07 & 4.1 & 1.41 & 9.9 & D .26 & .34 & 83.9 & 84.0 & I0028 \\
\hline 24 & 2903 & 12204 & 1.34 & .02 & 1.07 & 6.1 & 1.36 & 9.9 & E. 30 & 38 & 77.6 & 78.4 & I0024 \\
\hline 31 & 2436 & 12133 & 1.59 & .02 & 1.04 & 2.7 & 1.32 & 9.9 & F. 31 & .36 & 81.2 & 81.2 & I0031 \\
\hline 34 & 1676 & 11760 & 2.05 & .03 & 1.01 & .4 & 1.32 & 7.7 & G. 30 & .33 & 86.6 & 86.3 & I0034 \\
\hline 30 & 3114 & 12009 & 1.19 & .02 & 1.04 & 3.3 & 1.30 & 9.9 & Н. .34 & .39 & 77.5 & 76.9 & I0030 \\
\hline 27 & 2448 & 12169 & 1.59 & .02 & 1.01 & 1.0 & 1.25 & 8.2 & I .33 & .37 & 81.4 & 81.2 & I0027 \\
\hline 35 & 2485 & 12111 & 1.55 & .02 & 1.03 & 2.0 & 1.24 & 7.9 & J .33 & .37 & 80.9 & 80.9 & I0035 \\
\hline
\end{tabular}

\subsection{Fit Statistics}

The most common indices of the item are the information weighted index (IMS) and the unweighted index (the Outfit Mean Square or CSO). Table 4 provides information and statistics on all items included in APM. Based on the criteria [10] to examine the suitability of the items, it can be concluded that the overall items in the APM meet the criteria, meaning that there is no need to have the questions removed or replaced.

Various psychological attributes as measured by psychological tests can be predictors of future individual behavior, especially with regard to the placement of decisions that will be taken by the client. These psychological attributes are abilities, interests, and personality. These three things are quite stable factors in individuals in determining academic decisions and placement.

\subsection{Content Validity}

The construct validity of the APM scale (unidimensional test) by considering the raw-variance index is obtained by $29.0 \%$, close to the number 0.30 $(30 \%)$. This means that the items on the Indonesian version of the APM scale have a good category in measuring the diversity of respondents' abilities and are also able to measure one variable comprehensively.
The validity of APM items produced a positive number at $p<0.05$. This means that the validity of all APM items adapted into Indonesian culture can be correctly perceived by respondents. The Cronbach alpha value is 0.86 , including the good category. The unidimensional index is $36.5 \%$, including good categories [12]. According to Reference [8], if analyzed the questions in set II include problems that can be a measuring tool for all integral and analytical operations that exist in the process of high thinking. That is why APM is very useful for getting a review of the speed and success of learning that someone might achieve in a field of study.

In some literature $[10,16,17,18]$, it is stated that intelligence test scores are always interpreted based on their comparison with the scores in their groups. Therefore, the norm used always lists the age group. On the other hand, based on the results of the trial, it was also found that the total intelligence test scores (especially APM), from children to late adolescents (students), total scores rose, whereas in adults it tends to decrease along with increasing age. This can be explored from the results of the following trials.

In reliability testing, from children to adults the reliability figures are increasing. For example, based on the results of Reference [2], the re-test obtained reliability figures of 0.76 for children aged 10.5 years, 0.86 for the age group of 12.5 years, and 0.91 for the student group 
and adult. The results of these trials indicate that the higher the age level (school), the higher the level of reliability.

\subsection{Differential Item Functioning}

Differential Item Functioning (DIF) is a bias in measurement, meaning that an item is more in favor of one individual with certain characteristics, while on the other hand the opposition is harmed. For example, in item APM number 17, from the DIF curve, it can be seen that item number 17 is easier to answer correctly by women than men with a significant difference. Curve 1 describes the DIF of items in APM. The criteria for determining DIF are items that have a prob value of $<0.05$, based on these criteria there are 3 questions that have contracted DIF. John Carroll, for example, sees someone gifted in terms of the time needed to do a task or work. The less time needed to do a task, it is said to be more talented [19]. This DIF is also theoretically able to distinguish between gifted and regular students. While according to Woodworth and Marquis, talent is the results that can be predicted and can be measured by specially arranged tests. According to him, talent is included in the group of abilities. Guilford defines that talent refers to the ability to act. He said that the number of aptitude tests is the same as the number of activities that can be done. According to him, talent has three dimensions, namely perceptual dimensions, psychomotor dimensions, and intellectual dimensions. Each dimension includes more specific psychological factors, such as remembering abilities, reasoning abilities, and so on. This study also illustrated the APM that can truly express intellectual abilities as objectively as possible, and is neutral from cultural influences. 
Table 5. Differential Item Functioning

\begin{tabular}{|c|c|c|c|c|c|c|c|c|c|c|c|c|c|c|c|}
\hline \multirow{2}{*}{$\begin{array}{l}\text { Person } \\
\text { CLASS }\end{array}$} & \multirow{2}{*}{$\begin{array}{c}\text { DIF } \\
\text { Measure }\end{array}$} & \multirow{2}{*}{$\begin{array}{l}\text { DIF } \\
\text { S.E. }\end{array}$} & \multirow{2}{*}{$\begin{array}{c}\text { Person } \\
\text { Class }\end{array}$} & \multirow{2}{*}{$\begin{array}{c}\text { DIF } \\
\text { Measure }\end{array}$} & \multirow{2}{*}{$\begin{array}{l}\text { DIF } \\
\text { S.E. }\end{array}$} & \multirow{2}{*}{$\begin{array}{c}\text { DIF } \\
\text { Contrast }\end{array}$} & \multirow{2}{*}{$\begin{array}{l}\text { JOINT } \\
\text { S.E. }\end{array}$} & \multicolumn{3}{|c|}{ Welch } & \multicolumn{4}{|c|}{ Mantel-Haenszei Size Item } & \multirow{2}{*}{ Name } \\
\hline & & & & & & & & $\mathrm{t}$ & d.f. & Prob. & Chi-squ & Prob. & CUMLOR & Number & \\
\hline & -2.34 & 1.12 & $*$ & -1.01 & .96 & -1.33 & 1.47 & -.90 & 11 & .3852 & & & & 2 & $\mathrm{I} 0002$ \\
\hline & -2.34 & 1.12 & 0 & -1.68 & .62 & -.66 & 1.28 & -.52 & 16 & .6131 & & & & 2 & I0002 \\
\hline & -2.34 & 1.12 & 1 & -1.70 & .10 & -.63 & 1.12 & -.56 & 9 & .5863 & & & & 2 & I0002 \\
\hline & -2.34 & 1.12 & 2 & -1.78 & .15 & -.56 & 1.13 & -.50 & 10 & .6302 & & & & 2 & $\mathrm{I} 0002$ \\
\hline & -2.34 & 1.12 & 3 & -1.33 & .27 & -1.01 & 1.15 & -.88 & 12 & .3965 & & & & 2 & $\mathrm{I} 0002$ \\
\hline & -2.34 & 1.12 & 4 & -1.66 & .15 & -.68 & 1.13 & -.60 & 10 & .5619 & & & & 2 & $\mathrm{I} 0002$ \\
\hline & -2.34 & 1.12 & 5 & -2.07 & .03 & -.27 & 1.12 & -.24 & 8 & .8168 & .3333 & .5637 & & 2 & I0002 \\
\hline & -2.34 & 1.12 & 6 & -.92 & .30 & -1.42 & 1.16 & -1.23 & 12 & .2438 & .0000 & 1.000 & & 2 & $\mathrm{I} 0002$ \\
\hline & -2.34 & 1.12 & 7 & -.90 & .11 & -1.43 & 1.12 & -1.28 & 9 & .2339 & & & & 2 & $\mathrm{I} 0002$ \\
\hline & -2.34 & 1.12 & 8 & -1.61 & .13 & -.72 & 1.13 & -.64 & 9 & .5368 & & & & 2 & I0002 \\
\hline & -2.34 & 1.12 & $*$ & -2.06 & 1.15 & -.28 & 1.60 & -.17 & 10 & .8670 & & & & 3 & I0003 \\
\hline & -2.34 & 1.12 & 0 & -2.09 & .66 & -.25 & 1.30 & -.19 & 16 & .8513 & & & & 3 & $\mathrm{I} 0003$ \\
\hline & -2.34 & 1.12 & 1 & -1.86 & .10 & -.47 & 1.12 & -.42 & 9 & .6841 & & & & 3 & I0003 \\
\hline & -2.34 & 1.12 & 2 & -1.88 & .15 & -.45 & 1.13 & -.40 & 10 & .6964 & & & & 3 & I0003 \\
\hline & -2.34 & 1.12 & 3 & -1.47 & .27 & -.87 & 1.15 & -.75 & 12 & .4664 & & & & 3 & I0003 \\
\hline & -2.34 & 1.12 & 4 & -1.15 & .15 & -1.19 & 1.13 & -1.06 & 10 & .3160 & & & & 3 & I0003 \\
\hline & -2.34 & 1.12 & 5 & -2.14 & .03 & -.20 & 1.12 & -.18 & 8 & .8617 & .3333 & .5637 & & 3 & I0003 \\
\hline & -2.34 & 1.12 & 6 & -1.39 & .28 & -.95 & 1.15 & -.82 & 12 & .4274 & & & & 3 & I0003 \\
\hline & -2.34 & 1.12 & 7 & -1.06 & .11 & -1.27 & 1.12 & -1.13 & 9 & .2858 & & & & 3 & I0003 \\
\hline & -2.34 & 1.12 & 8 & -1.99 & .14 & -.34 & 1.13 & -.30 & 10 & .7667 & & & & 3 & $\mathrm{I} 0003$ \\
\hline & -1.67 & .86 & $*$ & $-3.16>$ & 1.57 & 1.50 & 1.79 & .84 & 8 & .4275 & & & & 4 & I0004 \\
\hline & -1.67 & .86 & 0 & -3.16 & .83 & 1.50 & 1.20 & 1.25 & 20 & .2244 & & & & 4 & I0004 \\
\hline & -1.67 & .86 & 1 & -1.94 & .10 & .27 & .87 & .31 & 9 & .7635 & .0000 & 1.000 & & 4 & I0004 \\
\hline & -1.67 & .86 & 2 & -1.55 & .14 & -.12 & .88 & -.14 & 10 & .8936 & & & & 4 & I0004 \\
\hline & -1.67 & .86 & 3 & -1.48 & .27 & -.19 & .91 & -.21 & 13 & .8396 & & & & 4 & I0004 \\
\hline & -1.67 & .86 & 4 & -1.58 & .15 & -.09 & .88 & -.10 & 10 & .9207 & & & & 4 & I0004 \\
\hline
\end{tabular}


APM standardization was first carried out in 1938 using data from 1407 samples of children in Ipswich, England, while norms for adults were developed during the Second World War [8]. The second standardization was carried out in 1979 because several studies [7] showed an increase in scores compared to the Ipswich norm [8]. Responding to the results of the second standardization in 1979, which indeed ultimately showed an increase when compared to the norm Ipswich, Raven argued that the increase in inter-time scores did not only occur in the APM but also in other test kits, which measure educational ability. This reinforces the opinion of Reference [20], which states that IQ scores have increased over time. Therefore, it becomes important in the use of an intelligence measurement tool for providing an interpretation of test results based on current norms.

The experts have provided an explanation of the nature and understanding of intelligence and its measurement through various approaches. "The approach in question is a philosophical, pragmatic, theoretical, and operational approach" $[5,20]$. APM as an instrument for measuring intelligence is characterized by (1) difficulty, (2) complexity, (3) abstraction, (4) economic, (5) goal-directed, (6) social value, and (7) containing authenticity; and to maintain activities in conditions that challenge energy and resist emotional stress, as described in this study.

\section{Conclusions}

The strength of this study is that the sample size is quite large, amounting to 12,343 people even though it is in a relatively homogeneous age range (16-19 years). This could be the strength of this research in contributing norms because the biggest users of this test are in the education area (school). APM can be used by psychological service institutions to develop population norms specifically for school children, especially at the senior secondary level. In practice, APM is a tool that psychology service institutions still use to deal with cases of aptitude test for high school students, related to majors if they continue to pursue higher education. APM is routinely used in recent years, and is massive (almost comprehensive in all schools); in the sense that APM is administered based on needs in the context of the selection or mapping of potential high school students.

Based on the results of the analysis, it can be concluded that the Advanced Progressive Matrices test is reliable according to the Alpha coefficient method. Items in APM meet the eligibility requirements of an instrument. Thus, for further research, it can target the age groups of students in different education levels and can be investigated for diagnostic uses of APM with specialized groups, such as special groups of intelligent individuals and groups of individuals with intellectual disabilities.

\section{Acknowledgements}

The authors wish to thank Universitas Pendidikan Indonesia for funding and supporting this research. We also thank the students and teachers who actively participated in this research.

\section{Appendix}
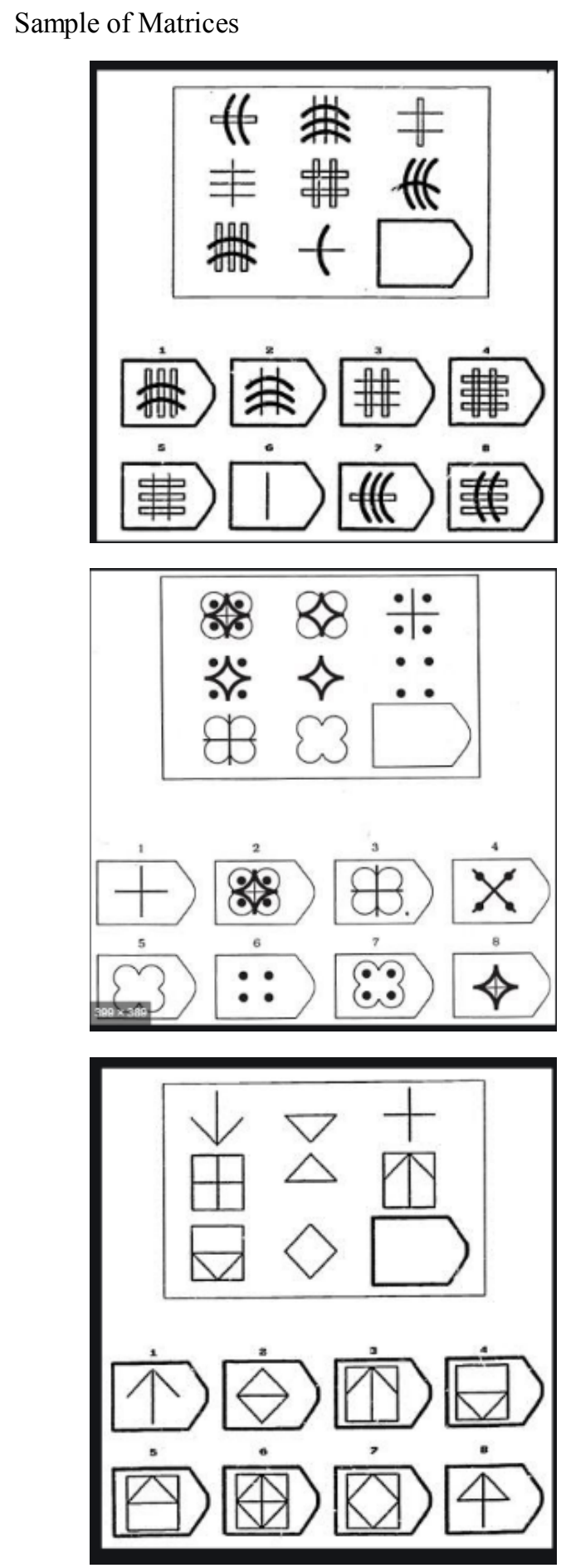


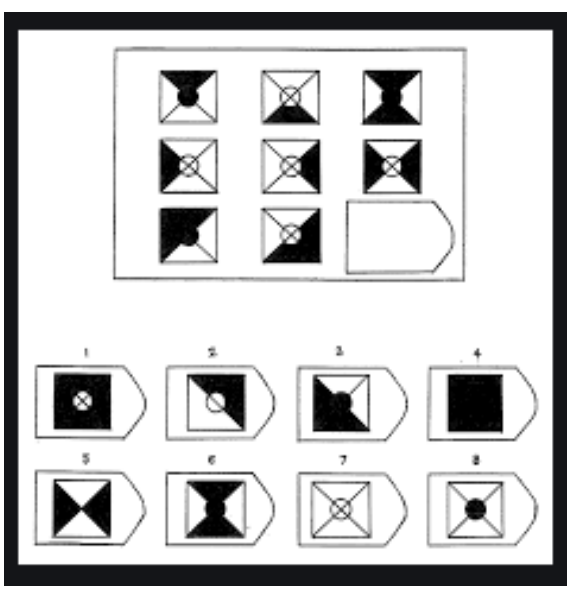

\section{REFERENCES}

[1] R. Knight, Book Reviews, The Philosophical Quarterly, Volume 1, Issue 5, October 1951, Pages 470-471, https://doi.org/10.2307/2216329

[2] P. Loesche, J. Wiley, \& M. Hasselhorn. How knowing the rules affect solving the Raven Advanced Progressive Matrices Test. Intelligence, Vol. 48, 58-75, 2015. https://doi.org/10.1016/j.intell.2014.10.004

[3] A. W. Paolitto, \& J. A. Naglieri. Stanford-Binet Intelligence Scale. In Encyclopedia of psychology, Vol. 7, 461-463, 2000. https://doi.org/10.1037/10522-192

[4] K. Cockcroft, \& N. Israel. The Raven's Advanced Progressive Matrices: A comparison of relationships with verbal ability tests. South African Journal of Psychology, Vol. 41, No. 3, 363-372, 2011.

[5] K. A. Becker. History of the Stanford-Binet Intelligence Scales: Content and Psychometrics. (Stanford-Binet Intelligence Scales, Fifth Edition Assessment Service Bulletin No. 1). Riverside Publishing, Itasca, 2003.

[6] V. M. Leavitt, \& E. Weber. Advanced Progressive Matrices. In: Kreutzer J.S., DeLuca J., Caplan B. (eds) Encyclopedia of Clinical Neuropsychology. Springer, Cham, 2018.

[7] D. A. Bors, \& F. Vigneau. The effect of practice on Raven's Advanced Progressive Matrices. Learning and Individual Differences, Vol 13, No. 4, 291-312, 2003.

[8] R. J. John. Raven Progressive Matrices. In: McCallum R.S. (eds) Handbook of Nonverbal Assessment. Springer, Boston, 2003

[9] E. S. Yudha, S. Kartadinata, \& N. Rusmana. Gifted Innovation Education: New Perspective in Identification and Development of Gifted Student in Inclusion Education Setting. Proceedings of the 1st International Conference on Social and Political Development (ICOSOP 2016), 56-63, 2017.

[10] R. Colom, \& F. J. Abad. (2007). Advanced Progressive Matrices and Sex Differences: Comment to Mackintosh and Bennett (2005). Intelligence, Vol. 35, No. 2, 183-185, 2007.
[11] R. Hamel, \& V. D. Schmittmann. The 20-Minute Version as a Predictor of the Raven Advanced Progressive Matrices Test. Educational and Psychological Measurement, Vol 66, No. 6, 1039-1046, 2006

[12] W. J. Boone, M. S. Yale, \& J. R. Staver. Rasch analysis in the human sciences. In Rasch Analysis in the Human Sciences. Springer, Dordrecht, 2014.

[13] D. L. McArthur. The Rasch Model for Item Analysis. In McArthur D.L. (eds) Alternative Approaches to the Assessment of Achievement. Evaluation in Education and Human Services, vol 16. Springer, Dordrecht, 1987.

[14] A. Tennant, S. P. McKenna, \& P. Hagell. (2004). Application of Rasch analysis in the development and application of quality of life instruments. Value in Health, Vol. 7, No. 1, S22-S26, 2004.

[15] A. H. G. S. Van Der Ven, \& J. L. Ellis. A Rasch analysis of Raven's standard progressive matrices. Personality and Individual Differences, Vol. 29, No. 1, 45-64, 2000.

[16] S. Akbari Chermahini, M. Hickendorff, \& B. Hommel Development and validity of a Dutch version of the Remote Associates Task: An item-response theory approach. Thinking Skills and Creativity, Vol. 7, No. 3, 177-186, 2012.

[17] F. Chiesi, M. Ciancaleoni, S. Galli, \& C. Primi. Using the advanced progressive matrices (Set I) to assess fluid ability in a short time frame: An item response theory-based analysis. Psychological Assessment, Vol. 24, No. 4, 892900, 2012.

[18] J. P. Rushton, M. Skuy, \& T. A. Bons. Construct Validity of Raven's Advanced Progressive Matrices for African and Non-African Engineering Students in South Africa. International Journal of Selection and Assessment, Vol. 12, No. 3, 220-229, 2004

[19] R. J. Havighurst. Developmental tasks and education. University of Chicago Press, Chicago, 1948.

[20] J. A. Sefcek, G. F. Miller, \& A. J. Figueredo. Development and Validation of an 18-Item Medium Form of the Ravens Advanced Progressive Matrices. SAGE Open, Vol. 6, No. 2, 2016. 